\title{
A PANDEMIA DO NOVO CORONAVÍRUS (SARS-COV-2) E SUAS REPERCUSSÕES NA ESTIGMATIZAÇÃO E O PRECONCEITO
}

\author{
THE PANDEMIC OF THE NEW CORONAVIRUS \\ (SARS-COV-2) AND ITS REPERCUSSIONS ON \\ STIGMATIZATION AND PREJUDICE
}

\section{LA PANDEMIA DEL NUEVO CORONAVIRUS (SARS-COV-2) Y SUS REPERCUSIONES EN LA ESTIGMATIZACIÓN Y LOS PREJUICIOS}

\author{
Gilvânia Patrícia do Nascimento Paixão \\ Rudval Souza da Silva ${ }^{2}$ \\ Fernanda Nassiff Neves Carneiro ${ }^{3}$ \\ Leiza Nazareth Torres Lisbôa ${ }^{4}$
}

Como citar este artigo: Paixão GPN, Silva RS, Carneiro FNN, Lisbôa LNT. A pandemia do novo coronavírus (SARS-CoV-2) e suas repercussões na estigmatização e o preconceito. Rev baiana enferm. 2021;35:e36986.

\begin{abstract}
Objetivo: refletir acerca do cenário do novo Coronavírus no que tange à estigmatização e o preconceito para com as pessoas infectadas. Método: ensaio de reflexão teórico-filosófica. Resultados: uma crise atual e presente inclusive no cotidiano dos profissionais de saúde que estão na linha de frente da produção do cuidado junto às pessoas que têm desenvolvido a doença da COVID-19 e lotado as unidades de saúde. Panorama que se assemelha a uma guerra, todavia com armamento invisível e letal que desponta num cenário de mortes, gerando medo e ansiedade em toda a população mundial, além de propiciar disfunções sociais. Conclusão: a discussão sobre a estigmatização remete aos estudos de Erving Goffman e à definição de estigma e sua repercussão na identidade da pessoa com distorções e comprometimentos emocional e social, o que tem influenciado o cotidiano de pessoas contaminadas pelo novo coronavírus marcado pela estigmatização e preconceito social.
\end{abstract}

Descritores: Infecções por Coronavírus. Pandemias. Estigma social. Medo. Ansiedade.

Objective: to reflect on the scenario of the new Coronavirus regarding stigmatization and prejudice towards infected people. Method: theoretical-philosophical reflection essay. Results: a current and present crisis even in the daily life of health professionals who are on the front line of the production of care with people who have developed COVID-19 and crowded the bealth units. Panorama that resembles a war, however with invisible and lethal weaponry that emerges in a scenario of deaths, generating fear and anxiety in the entire world population, besides providing social dysfunctions. Conclusion: the discussion about stigmatization refers to the studies of Erving Goffman and the definition of stigma and its repercussion on the identity of the person with distortions and emotional and social

Enfermeira. Doutora em Enfermagem. Professora na Universidade do Estado da Bahia. Juazeiro, Bahia, Brasil. http://orcid.org/0000-000 I-6539-482X.

Enfermeiro. Doutor em Enfermagem. Professor na Universidade do Estado da Bahia. Senhor do Bonfim, Bahia, Brasil. rudvalsouza@yahoo.com.br. http://orcid. org/0000-0002-7991-8804.

3 Enfermeira. Universidade do Estado da Bahia. Salvador, Bahia, Brasil. http://orcid.org/0000-000 I-8045-2 I 00.

4 Psicóloga. Universidade do Estado da Bahia. Salvador, Bahia, Brasil. http://orcid.org/0000-000 I-80 1 2-7770. 
impairments, which has influenced the daily lives of people infected by the new coronavirus marked by stigmatization and social prejudice.

Descriptors: Coronavirus Infections. Pandemics. Social Stigma. Fear. Anxiety.

Objetivo: reflexionar sobre el escenario del nuevo Coronavirus con respecto a la estigmatización y los prejuicios hacia las personas infectadas. Método: ensayo teórico-filosófico de reflexión. Resultados: una crisis actual y presente incluso en la vida cotidiana de los profesionales de la salud que están en la línea frontal de la producción de atención con personas que han desarrollado la enfermedad de COVID-19 y han abarrotado las unidades sanitarias. Panorama que se asemeja a una guerra, sin embargo con armamento invisible y letal que emerge en un escenario de muertes, generando miedo y ansiedad en toda la población mundial, además de proporcionar disfunciones sociales. Conclusión: la discusión sobre la estigmatización se refiere a los estudios de Erving Goffman y la definición del estigma y su repercusión en la identidad de la persona con distorsiones y discapacidades emocionales y sociales, lo que ba influido en la vida cotidiana de las personas infectadas por el nuevo coronavirus marcado por la estigmatización $y$ los prejuicios sociales.

Descriptores: Infecciones por Coronavirus. Pandemias. Estigma Social. Miedo. Ansiedad.

\section{Introdução}

Do "atchim" vem reações que variam desde o "sai para lá que você está com COVID-19" à agressão física. As atitudes de desrespeito para com o próximo têm se mostrado de modo exacerbado e violento, como a que ocorreu recentemente numa capital do Nordeste, em que uma usuária de drogas foi agredida num transporte público e expulsa a pontapés por espirrar sem máscara ${ }^{(1)}$. Esse é parte do cenário que estamos vivendo em tempos de pandemia.

A pandemia não é algo comum, mas faz parte da história da humanidade, podendo-se mencionar a Gripe Espanhola que ceifou vidas entre os anos de 1918 e 1920 quando infectou cerca de 600 milhões de pessoas, número que representou, naquela época, cerca de um quarto da população mundial ${ }^{(2)}$. Esta é considerada, até o momento, como a maior e mais grave crise por doenças infecciosas que atingiu o mundo, quando, num curto espaço temporal de menos de três anos, ocorreram entre 20 e 100 milhões de mortes em consequência de suas graves complicações respiratórias. Esse número é maior do que as mortes decorrentes de três guerras juntas: I Guerra Mundial, Guerras do Vietnã e da Coreia ${ }^{(3)}$.

Naquela época, autoridades sanitárias internacionais viram-se diante de um grande mistério: Como uma simples gripe veio a provocar tanta desordem social e mortes? Eis que, após um século desse episódio pandêmico, nos deparamos com um cenário semelhante, preocupante, ainda em desenvolvimento e marcado por incertezas. Por ser uma doença recente, a COVID-19 guarda aspectos desconhecidos em relação à sua origem, fisiopatologia e manejo. Sabe-se, no entanto, que o novo coronavírus (Sars-CoV-2) tem um alto poder de transmissibilidade, haja vista a disseminação em todo o mundo em apenas dois meses $^{(4)}$. Até o momento em que este ensaio estava sendo redigido, início de junho de 2020, mais de 7.410.510 casos de COVID-19 foram confirmados e mais de 418.294 vidas ceifadas em todo o mundo em decorrência dessa doença ${ }^{(5)}$. Destes números, as cifras no Brasil atingem 850.514 casos confirmados com o número de mortes ultrapassando 42.000 óbitos. Vale destacar no cenário nacional, 379.514 pacientes recuperados, equivalente a $44,59 \%$ dos casos confirmados $^{(6)}$.

Como medidas básicas e eficientes para conter a rápida propagação desse agente, as práticas do "distanciamento social" de toda população, além do "isolamento dos doentes" e da "quarentena" dos possíveis infectados, têm sido altamente recomendadas em todos os países do mundo. Frente a isso, as pessoas passaram a modificar 
toda a sua rotina, como também adquirir novos hábitos, principalmente de higiene, como o uso de máscaras de proteção respiratória, uso de álcool gel e a lavagem frequente das mãos, o que tem se mostrado como artifícios eficazes quando se fala em proteção individual.

O presente ensaio de reflexão emergiu do cenário atual de pandemia que vem assolando todo o mundo e impactando em mudanças no cotidiano de toda a sociedade brasileira. Dentre esses impactos, vale destacar a reflexão acerca das questões relacionadas ao preconceito e à estigmatização social marcantes nesse momento, o que direcionou a escrita deste ensaio teórico.

Dessa forma, o objetivo deste ensaio é refletir acerca do cenário do novo Coronavírus no que tange à estigmatização e o preconceito para com as pessoas infectadas.

\section{Método}

Ensaio desenvolvido com base em uma reflexão teórico-filosófica, fundamentada nos estudos de Erving Goffman sobre estigma.

\section{Resultados e Discussão}

Tudo é muito recente, do início das primeiras notícias até a escrita deste ensaio menos de seis meses se passaram. Vive-se um momento de reaprendizagem das conformações sociais. O 2019-nCoV, classificado como Novel Coronavirus-Infected Pneumonia (NCIP), teve sua confirmação utilizando-se do lavado broncoalveolar, o qual passou por um estudo completo de sequenciamento de genoma, utilizando-se da técnica de reverse-transcriptase polymerase chain reaction (RT-PCR) naqueles pacientes que se encontravam hospitalizados em Wuhan, capital da província da China Central. Após essa análise, o famoso vírus foi catalogado no gênero betacoronavirus, o que engloba também o SARS-CoV, descobertos em humanos, morcegos e outros animais selvagens ${ }^{(7)}$.

Os primeiros casos confirmados na cidade de Wuhan, China Central, tiveram um perfil de pessoas com idade média de 49 anos, prevalecendo o sexo masculino, apresentando inicialmente a febre e a linfopenia como principais sinais, e sintomas, como tosse seca, dispneia, mialgia e fadiga, evoluindo para quadros mais graves resultando em óbitos ${ }^{(8)}$. Com o acompanhamento dos casos, passou a ser observado também os pacientes assintomáticos e aqueles com histórico de sintomas menos comuns, como confusão mental, cefaleia, congestão conjuntival, rinorreia, hemoptise, perda parcial (hiposmia) ou total (anosmia) do olfato, dor de garganta, náuseas e vômitos, redução da capacidade de sentir sabores (hipogeusia) ou perda do paladar (ageusia), dor torácica e casos de diarreia ${ }^{(9)}$.

Esse cenário, que parecia distante, chegou ao Brasil com resultados bastante negativos, especialmente pelo cenário de desigualdades sociais marcante no nosso país e sua característica peculiar de ser um país continental. Uma doença respiratória com alto poder de letalidade para a qual não há vacina, o que reforça o medo e a ansiedade entre a população, mesmo com a adoção das medidas preventivas preconizadas pela Organização Mundial de Saúde (OMS) ${ }^{10}$.

Nesse contexto de rápido aumento do número de casos e mortes, bem como a impossibilidade palpável de se vislumbrar um fim para a pandemia, os sentimentos afloram no íntimo das pessoas: medo e ansiedade. O temor de que a doença chegue ao "nosso" seio familiar, o receio de que a estatística de morte "nos" alcance, associados à desinformação e, para piorar a situação, o mau uso das mídias e redes sociais contribuindo para a infodemia (neologismo atribuído pela OMS ao excesso de informações, sejam elas confiáveis ou não, o que tem tornado difícil a seleção de informações idôneas) e as abomináveis Fake News ${ }^{(11)}$, que têm causado problemas de ordem social e emocional, com exacerbação do medo, da ansiedade e da impotência diante do caos mundial que a COVID-19 tem deixado, especialmente no que tange ao cenário de incertezas.

Partindo dessa problemática, entende-se ser relevante refletir acerca das repercussões inerentes à estigmatização e ao preconceito frente 
às pessoas infectadas pelo novo coronavírus. Essa discussão remete aos estudos de Goffman e à definição do que é o estigma ${ }^{(12)}$ e seus efeitos na identidade da pessoa ${ }^{(13)}$ com distorções e comprometimentos emocional e social.

Estigma é um termo marcante na trajetória da humanidade e vem da Grécia Antiga, todavia, somente a partir da década de 60 do século passado, passou a ser objeto de estudos e discussões com base em pesquisas desenvolvidas pelo sociólogo e antropólogo canadense Erving Goffman, que atribuiu conceitos que podem melhor compreender o estigma, mediante $\mathrm{O}$ entendimento de que a sociedade é partícipe do seu processo de formação. Em 1963, Goffman publicou a obra "Estigmas: Notas sobre a Manipulação da Identidade Deteriorada”"(12).

O conceito de estigma é permeado pela ideia da presença física entre "estigmatizados" e aqueles ditos "normais" "12). No contexto em que vivemos, essas pessoas seriam, respectivamente, as que estão infectadas ou mantêm contato com alguém doente, e as que se dizem não portadoras do novo coronavírus, valendo destacar que muitas delas se imaginam imunes, influenciadas pelo movimento anticiência, marcante na pós-modernidade.

Os gregos, que detinham conhecimento sobre os recursos visuais, criaram o termo "estigma" para fazer referência aos sinais corporais ou de comportamento, e assim evidenciar algo excepcional ou negativo acerca do status moral daqueles que apresentavam tal característica. Assim, o teórico reconhece que a sociedade é quem estabelece os meios de categorizações das pessoas ${ }^{(12)}$.

Em meio ao individualismo que impera na sociedade pós-moderna, na qual o confronto tem sido marcante, o estigma tem estado presente, em especial no momento de pandemia que se vivencia. Em geral, tem-se visto poucas atitudes de empatia e reflexão para ponderar e reconhecer que existem outros meios de prevenir a contaminação, sem ter que ferir o emocional e social do outro. Além dos atos desrespeitosos e até desumanos que uma parcela da população tem sido exposta, as atitudes estigmatizantes e de preconceitos têm aumentado e proliferado diante do individualismo excludente peculiar de produção capitalista.

Assim, o problema entre o estigmatizado e os ditos normais perpassa pela falta de compreensão acerca da situação que está se vivendo, do conceito de coletividade e de que o vírus pode atingir a qualquer pessoa, mesmo sabendo que, de acordo com a realidade de cada um, o risco de contaminação pode ser potencializado ou não. Nesse cenário, parece faltar o reinvestimento na compaixão como uma abordagem fundamental do ser humano.

A pandemia e a COVID-19 têm mostrado que uma pessoa saudável e um mundo saudável são condições equivalentes e não antagônicas $^{(14)}$, logo, não há espaço para preconceitos, muito menos para estigmatizar pessoas por ter contraído o vírus; pelo contrário, vivemos um momento que cobra solidariedade e um agir com compaixão, respeito e seguindo as recomendações sanitárias cabíveis em cada caso.

Retomando aos conceitos de Goffman, vale destacar o seu entendimento de que a pessoa estigmatizada tem duas identidades: uma real e outra virtual. A primeira caracteriza-se pelo conjunto de divisões e atributos que uma pessoa prova ter. Já a identidade virtual, caracteriza-se como conjunto de divisões e atributos que as pessoas têm para com o estranho que surge a sua frente. Assim, uma dada característica pode ser considerada como um estigma, principalmente quando se observa uma desarmonia entre as duas identidades sociais, seja ela a virtual ou a real $^{(12)}$.

Um cenário marcado pelo excesso de informações (infodemia) ${ }^{(11)}$, tem contribuído sobremaneira para a formação da identidade virtual do estigmatizador, o que tem causado desconfortos e sofrimentos na identidade real das pessoas que contraíram o novo coronavírus. Essas, além de viverem o medo diante de uma doença nova e cercada por incertezas - Covid-19 -, ao invés de receber apoio, passa a ter que conviver em condições que só favorecem a exacerbação do abalo emocional, sofrendo ameaças direta ou indiretamente de pessoas insensíveis, rechaçando a pessoa contaminada 
com palavras ou atitudes preconceituosas $\mathrm{e}$ estigmatizantes.

O estigma pode ocorrer em decorrência de três circunstâncias: abominações do corpo, culpas de caráter individual e os estigmas tribais ${ }^{(12)}$. No que tange aos cenários observados e mencionados neste ensaio, o estigma configura-se como uma circunstância marcada pela culpa individual e reforçada por crenças falsas e pelo medo exacerbado de ser estigmatizador em contrair a doença. Essas falsas crenças vêm muitas vezes de grupos marcados pelo ódio e por ideologias extremistas, em especial relacionadas ao movimento anticiência.

Cabe aqui trazer um recorte dos profissionais de saúde que têm atuado na linha de frente no cuidado a pacientes com a COVID-19. Tomando como referência o cenário no qual estão inseridos, essas pessoas recebem a marca de potencialmente contaminadas, sem ao menos ter uma confirmação laboratorial ou clínica, o que não deixa de ser uma possibilidade. Entretanto, estigmatizá-las e tratá-las com desrespeito e preconceito é uma atitude deplorável e nada empática com alguém que tem se arriscado para cuidar de pessoas doentes ou que estão morrendo, reforçando a percepção de que não está sendo vivenciado a nossa essência de compaixão e solidariedade enquanto seres humanos.

Nessa conjuntura, tendo em vista a particularidade dos profissionais do campo da Enfermagem de permanecerem maior parte do tempo junto ao paciente, especialmente no contexto hospitalar, matéria publicada no Jornal El País aponta que o Brasil já perdeu mais profissionais da Enfermagem para o novo coronavírus do que países como a Itália e Espanha juntos ${ }^{(15)}$. Desde que a crise se instalou no país, mais de 98 trabalhadoras da Enfermagem brasileira foram infectadas pelo novo coronavírus e evoluíram para a morte.

Possíveis fatores têm contribuído para a elevação desses índices, como a escassez e/ou não disponibilização de equipamentos de proteção individual (EPI). Quando disponibilizados, os EPI muitas vezes são de baixa qualidade e, quando do momento da desparamentação, marcado por uma mistura de ansiedade e medo, por vezes não são observados os adequados critérios da técnica. Além disso, vale destacar o não isolamento de parcela da população com maior vulnerabilidade, de profissionais idosas e outros grupos de riscos, mantida na linha de frente de atuação ${ }^{(15)}$.

Desse modo, por ser um grupo de risco para contrair a doença devido à proximidade com a parcela contaminada, os profissionais do campo da Enfermagem têm sofrido preconceito e estigmatização por parte de parcela da sociedade. Um ponto importante a destacar é o de que o "estigmatizador" não tem certeza alguma de que ele não é um portador assintomático, até por ser notório de que não está sendo feito testagem em massa, e ainda se vivencia um cenário de escuridão, incertezas e falta de informações sobre quem de fato foi testado e tem um diagnóstico.

Tais atitudes estigmatizantes e preconceituosas não se configuram como ações saudáveis no contexto de intercâmbio social cotidiano entre seres humanos, causando transtornos emocionais e sociais na pessoa que sofre o estigma diante de atitudes hostis e desumanas. Cabe ressaltar o papel individual na prevenção da contaminação e da transmissão do coronavírus, pois, se cada um zelar pelo autocuidado, respeitar as orientações de higiene e o distanciamento social, as chances de contágio reduzem exponencialmente.

$\mathrm{Na}$ sua obra "A Representação do Eu na Vida Cotidiana" Goffman discute como o conceito do self apresenta-se no dia a dia, representado pelo cenário de medo e ansiedade que está se vivendo nesse contexto pandêmico, associado ao preconceito que vem atingindo o self das pessoas que tem contraído o vírus ${ }^{(13)}$. Compreender esse cotidiano é condição relevante para o entendimento dos comportamentos estigmatizantes pelo qual as pessoas passam a orientar suas ações na vida diária. Esse comportamento de repetições com palavras ou atitudes agressivas, apontando e expondo pessoas contaminadas, marca o self do estigmatizado e torna-se maior com a infodemia e a desinformação, condições nas quais a notícia 
6

A pandemia do novo coronavírus (SARS-CoV-2) e suas repercussões na estigmatizaçãoe o preconceito

se propaga na velocidade da luz e muitas vezes de modo negativo, com as já mencionadas Fake News.

Pode-se exemplificar com uma situação na qual uma pessoa apresenta sinais clínicos de tosse, febre, cansaço e ageusia, levando à suspeita de que se trata de um caso da COVID-19. Entende-se que a orientação é o distanciamento físico, mas que este se faça de modo respeitoso, e não como tem ocorrido, com exposição (com fotos em redes sociais), atitudes preconceituosas e estigmatização do outro, que mesmo após a cura clínica tem que lidar com essas reações. Com base nesse cenário, o estigmatizador define uma situação e orienta o seu agir com afronto aos valores e direitos humanos, não se dando conta das marcas que deixam no self do estigmatizado $^{(12)}$.

Claro que o medo é compreensível, mas é inaceitável a falta de sensibilidade, compaixão e solidariedade para com o sofrimento do outro, que pode ou não estar contaminado, e que terá que viver momentos de pânico, de forma solitária, diante do seu espaço pessoal e daqueles que o cercam, com uma repercussão traumática no seu self.

Em síntese, um preconceito equivocado da situação tem causado constrangimento e consequentemente o estigma, afrontando os valores e direitos humanos, num momento que pede solidariedade social e a edificação de pontes que permitam a passagem de atitudes de solidariedade e compaixão ${ }^{(16)}$.

\section{Conclusão}

Diante do exposto, vale refletir que de fato a situação remete ao aumento do medo, em especial do medo da morte, assim como da exacerbação da ansiedade. Associado a essas respostas humanas, cabe um pouco de racionalidade e de ter o cuidado para com o self do outro, reconhecendo o humano que existe em cada pessoa, e a necessidade de exercer a compaixão, a solidariedade e o respeito para com o outro.

Dessa forma, é preciso assumir a compaixão e a solidariedade como sentimentos e valores humanos e as medidas sanitárias de proteção individual e coletiva como forma de prevenção, adotando o distanciamento social ou O isolamento quando indicado, além do uso de máscaras, álcool gel e a tão simples medida da lavagem das mãos, não se furtando da reflexão quanto aos impactos no self das pessoas em situação de maior vulnerabilidade, como aquelas abaixo da linha da pobreza, moradores de rua e outros que necessitam de um olhar diferenciado por parte do poder público. Não se pode deixar de pontuar o zelo para com o uso adequado e respeitoso das mídias e redes sociais, evitando a infodemia, a disseminação excessiva de informações, as desinformações e as Fake News.

Estamos todos na torcida para que em breve tudo caminhe para dias melhores para muitos e de conforto emocional e espiritual para aqueles que passaram pela perda de um ente querido devido a Covid-19, mantendo o senso de compaixão e solidariedade em alerta para que, quando possível, se possa voltar a abraçar, segurar as mãos e agradecer por sobreviver a mais uma pandemia na história da humanidade.

\section{Colaborações:}

1 - concepção, projeto, análise e interpretação dos dados: Gilvânia Patrícia do Nascimento Paixão e Rudval Souza da Silva;

2 - redação do artigo e revisão crítica relevante do conteúdo intelectual: Gilvânia Patrícia do Nascimento Paixão, Rudval Souza da Silva, Fernanda Nassiff Neves Carneiro e Leiza Nazareth Torres Lisbôa;

3 - aprovação final da versão a ser publicada: Gilvânia Patrícia do Nascimento Paixão, Rudval Souza da Silva, Fernanda Nassiff Neves Carneiro e Leiza Nazareth Torres Lisbôa.

\section{Referências}

1. Correio da Bahia. Mulher expulsa a chutes de ônibus por estar sem máscara está internada [Internet]. Salvador; 2020 [cited 2020 Jun 13]. Available from: https://www.correio24horas.com. $\mathrm{br} /$ noticia/nid/mulher-expulsa-a-chutes-deonibus-por-estar-sem-mascara-esta-internada/ 
2. Silveira AJT. A medicina e a influenza espanhola de 1918. Tempo. 2005;10(19):91-105. DOI: https:// doi.org/10.1590/S1413-77042005000200007

3. Schlemper Junior BR, Dall'Oglio AC. A pandemia de influenza espanhola (1918) em Florianópolis, Santa Catarina, Brasil. ACM arq catarin med [Internet]. 2011 [cited 2020 Jun 13];40(3):104-14. Available from: http://www.acm.org.br/revista/ pdf/artigos/888.pdf

4. Stuart W, Frieman MB. COVID-19: knowns, unknowns, and questions. mSphere. 2020;5(2):e00203-20. DOI: 10.1128/mSphere. 00203-20

5. World Health Organization. Coronavirus Disease (COVID-19) pandemic [Internet]. Geneva (CHE); 2020 [cited 2020 Jun 13]. Available from: https://www.who.int/emergencies/diseases/ novel-coronavirus-2019

6. Brasil. Ministério da Saúde. COVID-19: Painel Coronavírus [Internet]. Brasília (DF); 2020 [cited 2020 Jun 13]. Available from: https://covid.saude. gov.br/

7. Tan WJ, Zhao X, Ma XJ. A novel coronavirus genome identified in a cluster of pneumonia cases: Wuhan, China 2019-2020. China CDC Weekly. 2020;2:61-2: DOI: 10.1056/NEJMoa2001017 https:// www.nejm.org/doi/full/10.1056/nejmoa2001017

8. Huang C, Wang Y, Li X, Ren L, Zhao J, Hu Y, et al. Clinical features of patients infected with 2019 novel coronavirus in Wuhan, China. Lancet. 2020;395(10223):497-506. DOI: 10.1016/ S0140-6736(20)30183-5

9. Lima CMAO. Information about the new coronavirus disease (COVID-19). Radiol Bras.
2020;53(2):V-VI. DOI: https://doi.org/10.1590/ 0100-3984.2020.53.2e1

10. Belasco AGS, Fonseca CD. Coronavírus 2020. Rev Bras Enferm. 2020;73(2):e2020n2. DOI: https://doi. org/10.1590/0034-7167-2020730201

11. Mesquita CT, Oliveira A, Seixas FL, Paes A. Infodemia, Fake News and Medicine: Science and The Quest for Truth. Int J Cardiovasc Sci. 2020;33(3):203-5. DOI: https://doi.org/10.36660/ ijcs. 20200073

12. Goffman E. Estigma: notas sobre a manipulação da identidade deteriorada. Rio de Janeiro: LTC; 1975.

13. Goffman E. A representação do eu na vida cotidiana. Petrópolis (RJ): Vozes; 1975.

14. Galea S. Compassion in a time of COVID-19. The Lancet. 2020;395(10241):1897-8. DOI: https:// doi.org/10.1016/S0140-6736(20)31202-2

15. Alessi G. Brasil já perdeu mais profissionais de enfermagem para o coronavírus do que Itália e Espanha juntas. El País [Internet]. 2020 May 1 [cited 2020 Jun 13]. Available from: https://brasil.elpais.com/brasil/2020-05-06/brasilja-perdeu-mais-profissionais-de-enfermagempara-o-coronavirus-do-que-italia-e-espanha-juntas. html

16. Organização das Nações Unidas. Coronavírus: representantes da ONU apontam estigma como "afronta aos valores e direitos humanos" [Internet]. Nova York (EUA); 2020 [cited 2020 May 12]. Available from: https://news.un.org/pt/ story/2020/03/1708832

Recebido: 26 de maio de 2020

Aprovado: 16 de junho de 2020

Publicado: 25 de novembro de 2020

A Revista Baiana de Enfermagem utiliza a Licença Creative Commons - Atribuição-NãoComercial 4.0 Internacional. https://creativecommons.org/licenses/by-nc/4.0/ Este artigo é de acesso aberto distribuído sob os termos da Licença Creative Commons (CC BY-NC). Esta licença permite que outros remixem, adaptem e criem a partir do seu trabalho para fins não comerciais. Embora os novos trabalhos tenham de lhe atribuir o devido crédito e não possam ser usados para fins comerciais, os usuários não têm de licenciar esses trabalhos derivados sob os mesmos termos. 